EESTI NSV TEADUSTE AKADEEMIA TOIMETISED. 20. KOIDE

KEEMIA * GEOLOOGIA. 197.1, NR. 1

ИЗВЕСТИЯ АКАДЕМИИ НАУК ЭСТОНСКОИ ССР. ТОМ 20

ХИМИЯ * ГЕОЛОГИЯ. 1971, № 1

ЛИА ПААЛЬМЕ, М. ГУБЕРГРНЦ

\title{
КИНЕТИКА ФОТОХИМИЧЕСКОГО ОКИСЛЕНИЯ 3,4-БЕНЗПИРЕНА, РАСТВОРЕННОГО В АЦЕТОНЕ
}

В предыдущих статьях $\left[{ }^{1,2}\right]$ охарактеризована кинетика деградации 3,4-бензпирена, растворенного в неполярных органических жидкостях различной природы - октане и бензоле, под воздействием ультрафиолетового облучения с широким диапазоном плины волн и при ограниченном доступе воздуха в систему. В $\left[{ }^{3}\right]$ приведены некоторые результаты исследования, в котором в качестве полярного растворителя используется ацетон. Существенная интенсификация процесса деградации канцерогена в этих условиях вызвала естественный интерес исследователей и побудила к более обстоятельному исследованию.

\section{Методика и результаты кинетического исследования}

Основная часть эксперимента проведена при постоянной интенсивности облучения $\left(1,7 \cdot 10^{15} \kappa в а н т / м \Omega \cdot с е \kappa\right)$, которая контролируется актинометрически по методике, описанной в [ $\left.{ }^{4}\right]$. В опытах варьировались: начальная концентрация 3,4-бензпирена в растворе - от 1,8 до $88,9 \cdot 10^{-5} M$ и длительность экспозиции (доза) - вплоть до 500 мин. Методика проведения кинетического эксперимента, обработки результатов и исследования продуктов описана в [1, 2 ]. В работе использованы реактивы высокой чистоты: 3,4-бензпирен фирмы Fluka AG, Buchs SG и ацетон марки «для спектроскопии».

Результаты первичной обработки полученных данных приводят к заключению, что суммарный процесс фотоокислительной деградации 3,4-бензпирена в ацетоне так же, как и в описанных ранее системах, соответствует макрокинетическому уравнению нулевого порядка. Определенные на этом основании значения констант скорости суммарной реакции, приведенные в таблице, сопоставлены с контантами деградации (молярная степень превращения 3,4-бензпирена в единицу времени) $\kappa^{\prime}$, $\left(c е \kappa^{-1}\right)$ и с данными для квантового выхода продуктов деградации.

\section{Обсуждение результатов исследования}

На рис. 1 приведены кривые, описывающие зависимость скорости суммарной реакции от начального уровня концентрации растворенного вещества. Кривая 1 отражает эту зависимость для раствора 3,4-бензпирена в ацетоне, кривые 2 и 3 построены для растворов в бензоле и октане. Общая тенденция к росту скорости превращения реагента по мере увеличения его концентрации (по затухающей экспоненциальной кривой) находит различное проявление в каждом конкретном случае в зависи- 
Макрокинетическая характеристика процесса фотолиза 3,4-бензпирена в ацетоне (интенсивность облучения $1,7 \cdot 10^{15}$ квант/мл. сек)

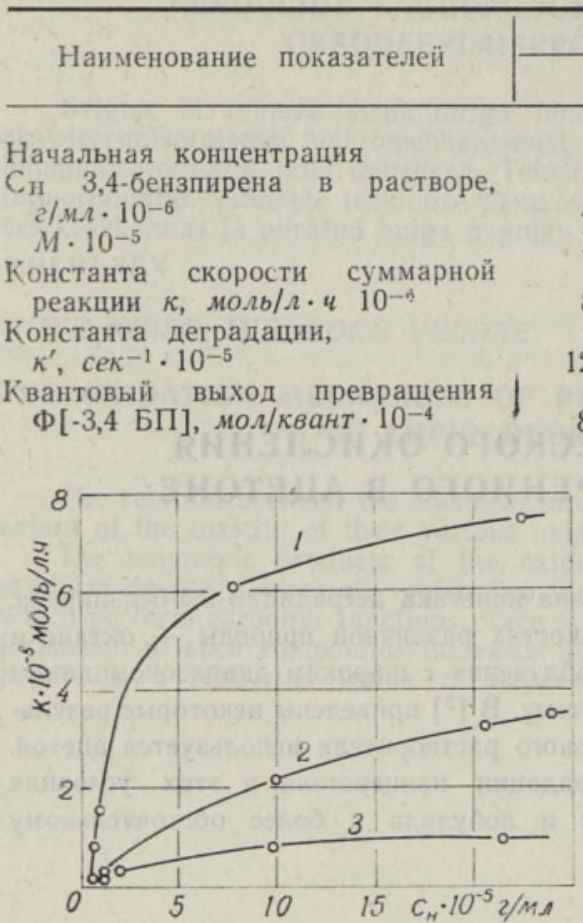

Рис. 1. Скорость суммарной реакции как функция начальной концентрации 3,4-бензпирена, растворенного в аце тоне $(1)$, бензоле (2) и октане (3) при мощности дозы $1,7 \cdot 10^{15} \kappa в а н т / м л \cdot$ сек.

мости от химической природы раст. ворителя. Как видно из рисунка, деградация бензпирена, растворенного в ацетоне, действительно отли-

чается резко повышенной (в 3-6 раз) интенсивностью при средних и относительно высоких концентрациях его в растворе по сравнению с системами в бензоле или октане. При низких же концентрациях, на уровне $1 \cdot 10^{-5} M$, скорость суммарного процесса во всех системах примерно одинакова, так как при большом разбавлении доминирует лишь концентрационный эффект.

Рассмотрение графического материала по изменению квантового выхода продуктов превращения бензпирена (рис. 2) приводит к заключению, что энергетическая эффективность процесса также возрастает с повышением концентрации растворенного вещества при использовании любого из растворителей, но достигает наибольшей величины для раствора в ацетоне. Абсолютное же значение этого показателя (см. таблицу) невелико и даже при использовании ацетона не превышает $8 \cdot 10^{-4}-7 \cdot 10^{-3}$ молекул на квант.

Воздействие концентрационного эффекта находит непосредственное отражение лишь в изменении константы деградации 3,4-бензпирена (см. таблицу), поскольку он не оказывает прямого влияния на величину константы скорости реакции нулевого порядка. Несмотря на увеличение 
вероятности столкновения и взаимодействия молекул растворенного вещества и, следовательно, протекания процесса деградации, этот показатель с повышением концентрации бензпирена снижается, а не возрастает. Это значит, судя по данным литературы [5], что атака молекулы канцерогена фотоном не влечет за собой непосредственное вступление последней в химическую реакцию, механизм которой является, по-видимому, относительно сложным.

Данные о степени превращения 3,4-бензпирена в ацетоне по сравнению с применением других растворителей $\left[{ }^{1-3}\right]$ вновь подтверждают своеобразное влияние его на интенсивность деградации канцерогена. Ключ ж объяснению этого явления можно найти, по-видимому, в итоге рассмотрения результатов исследования состава продуктов деградации 3,4-бензпирена в этом растворителе. Следует подчеркнуть при этом существенные трудности в их изучении в связи с чрезвычайно низкой их концентрацией и отсутствием в ряде случаев соответствующих эталонных спектров.

Спектры поглощения в ультрафиолетовой области для исходного раствора 3,4-бензпирена в ацетоне концентрацией $4 \cdot 10^{-5} M$ (кривая 1 ) и суммарной смеси продуктов его обработки при разных дозах (кривые 2-6) вплоть до практически лолного исчезновения канцерогена представлены на рис. 3. При этом об изменении состава реакционной смеси можно судить одновременно и на основании визуальных наблюдений, благодаря специфичному для продуктов окисления бензпирена изменению окраски в видимом свете.

Так, по мере увеличения дозы и снижения содержания 3,4-бензпирена происходит накопление первичных продуктов его окисления 3,4-бензпирен-5,8- и 5,10-дигидроксипроизводных, обладающих интенсивной желтой окраской (см. кривые 2

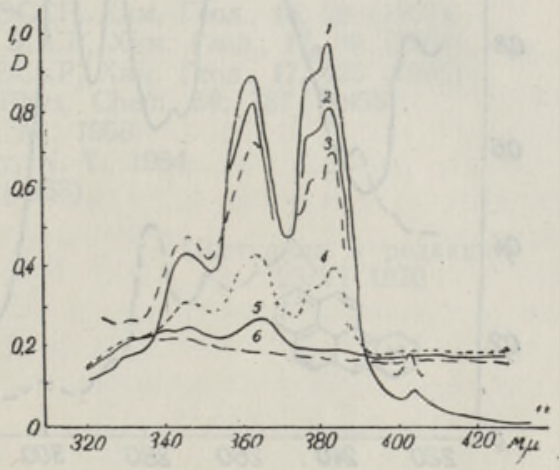

Рис. 3. Спектры поглощения облученного раствора 3,4-бензпирена в ацетоне:

1 - исходный необлучеиный раствор (бесцветный); 2 - после 0,5 ч облучення (желтый); 3 - после 1,0 ч облучення (интенсивно желтый): 4 - после 2,0 ч облучения сивно желтый): 4 - после 2,0 ч облучения
(оранжевый); 5 - после 3,0 ч облучения (желтоватый); 6 - после 5,0 ч облучения (бесцветный). и 3 на рис. 3). В дальнейшем, в системе наряду с их формированием протекает и, вероятно, становится доминирующей также вторичная реакция - окисление их до 5,8- и 5,10-хинонов (последнне удается выделить и идентифицировать по УФспектрам в итоге хроматографирования в тонком слое активной окиси алюминия с применением элюента бензол - ацетон в соотношении $9: 1)$, обладающих интенсивной оранжевой окраской (кривая 4). Наконец, на стадии исчерпания ресурсов исходного бензпирена реакционнал смесь вновь меняет окраску - от оранжевой на желтоватую и далее становится практически бесцветной. Результаты хроматографического разделения такой смеси приводят к заключению об участии бензпирендионов в реакциях ассоциативного характера, поскольку в ее состав входят соединения (неизвестного строения) с повышенным молекулярным весом. При этом, судя по данным литературы о механизме и составе продуктов фотолиза ацетона [5] и нашим «холостым» опытам с чистым растворителем, нельзя считать вероятным вовлечение последних в указан- 
ные ассоциативные реакции, как это оказалось возможным в случае фотодеградации в бензоле или октане $\left[{ }^{1,2}\right]$.

При хроматографическом разделении проб реакционной смеси с использованием другого элюента (смеси петролейного эфира и хлороформа в соотношении $9: 1)$ удается дополнительно выделить на пластине, наряду с областью концентрирования неразлсженного 3,4-бензпирена, две четко выраженные полосы. Одна из них $\left(R_{f}=0,55\right)$ расположена выше зоны размещения бензпирена и отличается зеленоватой флуоресценцией. Второй полосе $\left(R_{f}=0,38\right)$ свойственна синяя флуоресценция, она расположена ннже области концентрирования исходного реагента. После элюирования соответствующих фракций из этих полос и повторного разделения элюата в их составе по УФ-спектрам идентифицированы: продукт гидрирования пятого кольца - $1^{\prime}, 2^{\prime}, 3^{\prime}, 4^{\prime}$-тетрагидро-

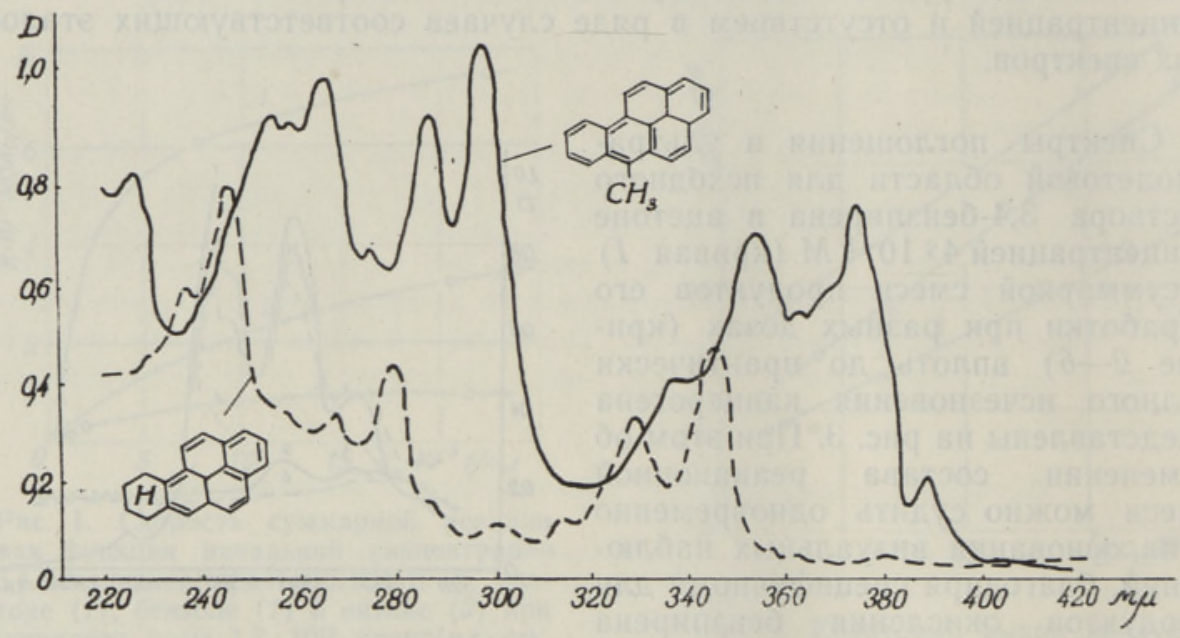

Рис. 4. Спектры поглощения продуктов, выделенных из облученного раствора 3,4-бензпирена в ацетоне.

3,4-бензпирен и алкилирования канцерогена с присоединением метильного радикала к наиболее активному пятому атому углерода в молекуле - 5-метил-3,4-бензпирен. Их спектры приведены на рис. 4.

\section{Заключение и выводы}

Анализ результатов кинетической части исследования приводит к заключению о том, что кинетические закономерности фотоокислительной деградации 3,4-бензпирена качественно не зависят от природы растворителя, которая сказывается, однако, весьма чувствительно на количественной характеристике процесса. При этом значения всех кинетических показателей убывают в ряду растворителей: ацетон $>$ бензол $>$ октан,

Суммарный процесс представляет собой комплекс реакций различных типов - последовательных и параллельных, в основном - окисления и ассоциации. На первой стадии окисления атаке кислорода подвергаются атомы углерода в положениях 5,8 и 10, которые обладают более выраженной высокой свободной валентностью при возбужденном состоянии молекулы, с образованием дигидроксипроизводных и дионов. В этом проявляется сходство изучаемого процесса с метаболическим превращением 3,4-бензпирена. Оно открывает принципиальную возможность 
моделировать in vitro некоторые процессы деградации канцерогенов, протекающие в живом организме.

В реакции ассоциативного характера, наряду с возбужденными молекулами канцерогена, выступают также продукты его более глубокого окисления. Этот процесс требует дальнейшего изучения.

Своеобразные свойства ацетона как растворителя и его поведение в процессе окислительного фотолиза позволили впервые непосредственно в эксперименте оценить специфическую для канцерогенов способность 3,4-бензпирена к одновременному проявлению электро-акцепторных и донорных свойств, установленную ранее лишь на основе квантово-химических расчетов или косвенным путем, по спектрам электронного парамагнитного резонанса $\left[{ }^{6,7}\right]$. Именно в этих свойствах канцерогена и данного растворителя кроется основная причина повышенной интенсивности фотоокислительной деградации 3,4-бензпирена, растворенного в ацетоне.

\title{
ЛИ ТЕРА Т Р А
}

1. Па альме Л., Г убергриц М., Изв. АН ЭССР, Хим. Геол., 16, 32 (1967).

2. Па альме Л., Губергриц М., Изв. АН ЭССР, Хим. Геол., 17, 99 (1968).

3. Па альме Л., Г убе ргр и М., Изв. АН ЭССР, Хим. Геол., 17,425 (1968).

4. B a xendale J. H., B ridge N. K., J. Phys. Chem. 59, 787 (1955).

5. К а льв ер т Дж., Пи т т Дж., Фотохимия, М., 1968.

6. Din er S., Electronic Aspects of Biochemistry, N. Y., 1964.

7. All is on A. C., N a sh T., Nature, 107, 758 (1963).

\author{
Ннститут химии \\ Академии наук Эстонской ССР \\ Поступила в редакциіо \\ 25/VI 1970
}

\section{LIA PAALME, M. GUBERGRITS}

\section{3,4-BENSPUREENI FOTOKEEMILISE MUUNDUMISE KINEETIKA AEREERITUD ATSETOONILAHUSES}

Artiklis esitatu on jätkuks 3,4-benspüreeni muundumise kineetika uurimisele aereeritud lahustajates ultraviolettiiirguse toimel.

Lahustaja olemus avalđab märgatavat mōju 3,4-benspüreeni lagunemise kvantitatiivsele küljele. 3,4-benspüreeni summaarne lagunemiskiirus ja lagunemisproduktide kvantsaagised suurenevad reas oktaan $<$ benseen $<$ atsetoon.

Lagunemisproduktide hulgast identifitseeritud 1,2,3,4-tetrahüdro-3,4-benspüreen, 5metüül-3,4-benspüreen, 3,4-benspüreen-5,8- ja $-5,10$-dioon kinnitavad eksperimentaalselt 3,4-benspüreeni elektron-doonorlust ja -akseptorlust, mis on kooskōlas olemasoleva teoreetilise käsitlusega.

\section{IIA PAALME, M. GUIBERGRITS}

\section{KINETICS OF 3,4-BENZOPYRENE PHOTOCHEMICAL DEGRADATION IN AERATED ACETONE SOLUTION}

The paper deals with the results of an experimental investigation concerning the kinetics of 3,4-benzopyrene degradation in aerated solutions under ultraviolet irradiatio;.

The nature of solvent strongly affects the macrokinetics of the photodegradation of 3,4-benzopyrene. The reaction rate and the quantum yield of the summary products of the photodegradation of the 3,4-benzopyrene increase in the order octane $<$ benzene $<$ acetone.

The theoretical interpretation of the electron donor and acceptor properties of 3.4benzopyrene are first shown practically by an identification of the photodegradation products of 3,4-benzopyrene in aerated acetone solution simultaneously with 5-methyl-3,4tenzopyrene, $1^{\prime}, 2^{\prime}, 3^{\prime}, 4^{\prime}$-tetrahydro-3,4-benzopyrene, 3,4-benzopyrene-5,8-,5,10-dione. 